\title{
The Measure and Definition of Access to Energy Systems by Households and Social Effects of Lack of Modern Energy Access
}

\author{
Gülbahar Bilgiç \\ Department of Energy Systems Engineering, Ankara Yıldırım Beyazıt University, Turkey
}

Copyright $\subset 2017$ by authors, all rights reserved. Authors agree that this article remains permanently open access under the terms of the Creative Commons Attribution License 4.0 International License

\begin{abstract}
Energy is fundamental to economic and social development; to reduce poverty and continue to grow. It supports people as they seek a whole range of development benefits: cleaner and safer homes, lives of greater dignity and less drudgery, to better livelihoods and better quality education and health services. At the same time, modern energy (such as natural gas, electricity) access is essential to provide, sanitation services, reliable and efficient lighting, heating, cooking, mechanical power, transportation and telecommunication. However, developing countries are unable to meet rising energy demands. Therefore, there are many problems in the rural areas far from city centers, which are caused by the lack of modern energy. This study highlights the importance of reaching modern energy, describes the minimum standards of it and examines the importance of this energy for households. Lack of modern energy access, a general explanation has been given about the social problems the household has experienced.
\end{abstract}

Keywords Access to Modern Energy, Household, Minimum Standards, Social Effects

\section{Introduction}

Energy systems are defined as a transmission and distribution network when energy or energy benefits are needed as needed. An energy system consists of the energy supply sector and energy end-use technologies. The aim of an energy system is to convey the benefits of energy to customers. Energy services are used to describe these benefits [1]. Energy services for households are lighting, cooking, proper indoor temperature, refrigeration, telecommunications, education and transport.

There is no single definition of energy access. But the most commonly used definition is:

- Household access to a minimum level of electricity.
- Household access to safer and more sustainable (i.e. minimum harmful effects on health and the environment as possible) cooking and heating fuels and stoves.

- Access to modern energy that enables productive economic activity, e.g. mechanical power for agriculture, textile and other industries.

- Access to modern energy for public services, e.g. electricity for health facilities, schools and street lighting [1].

What is modern energy system? There is a general agreement that households which use candles wick and hurricane kerosene lamps as a sole lighting source and which cook on three stone fires are considered to be energy poor. However, it has proved to be more difficult to define positively what access to "modern" energy technologies and services means. The owner of a torch (or flashlight) which he or she uses in addition to candles does certainly not have access to modern energy. But what about small solar home systems provides electricity for a few light bulbs and a radio? Can these small systems be considered as access to modern energy, or are they only "illuminating poverty"? Is "electricity access" at least enough to run refrigerators and other household appliances? Then, how many of them and which appliance is? We know that mechanical power for milling grain etc. is a critical energy supply to many small farmers but is "access" having an improved hand grinding tool, or a diesel mill in the village, or the next village? To answer these questions is not an easy task as there is no obvious minimum level allowing a clear definition of access to "modern" energy technologies and services. Gaining access to improved energy services is not a sudden event, but a continuous process of improvement. Thus, any definition of a minimum threshold for energy access is in a certain way arbitrary. However, if Universal Energy Access by 2030 as proposed by the UN Secretary General is to be a target which is achievable, ideally with recognizable milestones along the way, then some agreed definition of "access having been 
achieved" is necessary. Some experts argue that in the case of cooking energy, the step from biomass (firewood, charcoal) to LPG, gas or electricity and in the case of other energy needs, the connection to the national grid, should be defined as threshold for access. However, it can easily be seen that in practice many poor households with electricity from the grid gain no more than the light of a few bulbs for a few intermittent hours a night, leaving most development benefits claimed for energy access out of reach. Using biomass as a cooking fuel in an efficient stove which vents the smoke outside has very different implications on health, drudgery and environmental impact than cooking on a three stone fire in the kitchen. The Poor People's Energy Outlook 2010 (PPEO) sought to highlight some of these important underlying issues by focusing on the number and quality of the energy services which people enjoy and the quality of the energy supplies which people have to produce these services [2].

Energy access is one of the most important parameters for the development of countries. There is a strong relationship between energy access and economic development. No activity can be done without energy in areas such as industrialization, daily life, transportation and communication. Cooking, heating the home, benefiting from cultural activities, training cannot be the subject. Thus, energy access is a requirement for millions of people to reach basic living standards. The fuels used in rural areas, which have no access to modern energy systems, threaten human health as well as pollute the environment with particulates that they have at the same time. Poverty is a major obstacle not only to the developing countries but also to the development of the whole world at the same time. Today, poverty is defined as the inability to benefit from education, health and nutrition facilities in addition to economic deprivation. The level of income and economic activity of an individual depends largely on the number of years they have spent in education. That is, as education level increases, prosperity increases in proportion to the level. Increased energy access facilitates inputs that provide a quality education. For example, the use of smart boards in classrooms, photo-copying, laboratory practical tests, operating audio-visual equipment, security lights, water pumping, domestic science studies, cooking and boiling. All these services require energy. In the world, 291 million children (more than $50 \%$ of children in developing countries) go to primary schools without access to electricity [1]. Given the importance of balanced nutrition for child development and concentration, governments and non-governmental organizations in some developing countries are working to provide schools with meals. In addition to nutrition, cold, humid, and poorly ventilated classes create an uncomfortable environment and can cause health problems. Hot (at an average annual temperature of $30^{\circ} \mathrm{C}$ ) conditions can also exacerbate diseases as dehydration, fatigue and hot strikes.

Energy access is a requirement to cope with these multidimensional aspects of poverty. From the perspective of the poor, access to energy services (lighting, heating) is more important than reaching energy resources. Energy poverty still prevails in the developing world. Approximately 1.6 billion people in the world do not have access to electricity [3]. In Asia, where Turkey is also located, 100 million people still do not have access to electricity, which is one of the modern energy systems. [3]. But even though the data are in this direction, no detailed research has been done on access to modern energy systems in our country related to energy access. An estimated 1.2 billion people $-16 \%$ of the global population - did not have access to electricity, 15 million fewer than reported in the previous year [1]. Many more suffer from supply that is of poor quality. More than $95 \%$ of those living without electricity are in countries in sub-Saharan Africa and developing Asia, and they are predominantly in rural areas (around $80 \%$ of the world total). While still far from complete, progress in providing electrification in urban areas has outpaced that in rural areas two to one since 2000 [1]. In WEO-2016, more than 2.7 billion people - $38 \%$ of the world's population - are estimated to have relied on the traditional use of solid biomass for cooking, typically using inefficient stoves or open fires in poorly ventilated spaces. Developing Asia and sub-Saharan Africa once again dominate the global totals. While the number of people relying on biomass is larger in developing Asia than in sub-Saharan Africa, their share of the population is lower: $50 \%$ in developing Asia, compared with more than $80 \%$ in sub-Saharan Africa. Overall, nearly three-quarters of the global population living without clean cooking facilities (around 2 billion people) live in just ten countries [1].

\section{The Measure and Definition of Access to Energy Systems by Households}

Measuring energy access in a more accurate and appropriate way, informed by what really matters to poor people, throws new light on the problem of energy access. Energy supply index was developed to indicate progress on the supply side towards the energy service standards outlined above (Table 1). The index measures that are proposed as the three main supply dimensions of energy supplies household fuels, electricity and mechanical power. By assigning a numerical value to the qualitative dimensions of people's experience of accessing energy supplies (1 being the lowest and 5 the highest level of access) it proposes to cover the true variety of energy supply experiences within the have and have not binary [2].

Level 0: There is no access to electricity. Oil and gas often used candles for lighting. Fuel use is just simple and primitive. The use of mechanical device is not in question.

Level 1: Access to electricity is provided by batteries. In simple stove wood, plant and animal waste fuels are used.

Level 2: Access to the electrical coil is supplied with lamps and lanterns. Households use stoves for heating and cooking. Charcoal as fuel and biofuel can be used. To help 
animals are used in the home and garden work. Access to mechanical means is still lacking.

Level 3: Access is partly electric. Solar energy systems independent of the mains line is being used. Better designed stoves with smoke evacuation are being used. Small mechanical tools are used.

Level 4: Have access to safe and AC system, but this is not enough. DC systems are used. Solid and liquid fuels are used.

Level 5: The AC systems are used and reliable. Have access to electronic goods. Clean fuels are used.

A variety of approaches have been proposed to setting a minimum level of energy access from averaged measures in $\mathrm{kWh}$ or barrels of oil equivalent consumed per household, to "commercial" energy consumption measures [5]. However, such averaging approaches tend to dilute the information which is obtained making it very difficult to tell the real access difference between someone consuming $\mathrm{X} \mathrm{kWH}$ and $\mathrm{Y} \mathrm{kWh}$, out of the context of the services they are enjoying [2]. In the PPEO 2010, a definition of access was put forward proposing a defined range of energy services covering the range of services people want and need, along with proposed minimum levels for each of these which could be considered as "access" [4]. Table 2 illustrates, identifies energy supplies relevant to households, productive uses, and community services, with mechanical power included under productive uses. Important attributes specific to energy supply for productive uses and community services will be included in the framework. This will allow an assessment of levels of access to decentralize compared to grid-supplied electricity at national levels. In a second stage, the framework then looks at energy services. For household electricity this means the use of particular appliances such as a radio or mobile phone charging at lower tiers, up to a refrigerator and electric space heating and cooling at the highest tiers. For cooking, the features considered in terms of the energy service are around convenience (time spent on collecting and preparing fuel), conformity to ensure indoor air pollution is reduced, and adequacy to meet all local cooking needs [4].

Table 1. Energy supply index

\begin{tabular}{|c|c|c|}
\hline Energy supply & Level & Quality of supply \\
\hline Household Fuels & $\begin{array}{l}0 \\
1 \\
2 \\
3 \\
4 \\
5\end{array}$ & $\begin{array}{l}\text { Using non-standard solid fuels such as plastics, } \\
\text { Using solid fuel in an open/three-stone fire } \\
\text { Using solid fuel in an improved stone } \\
\text { Using solid fuel in an improved stove with smoke extraction/chimney } \\
\text { Mainly using a liquid or gas fuel or electricity, and associated stove } \\
\text { Using only a liquid or gas fuel or electricity, and associated stove }\end{array}$ \\
\hline Electricity & $\begin{array}{l}0 \\
1 \\
2 \\
3 \\
4 \\
5\end{array}$ & $\begin{array}{l}\text { No access to electricity at all } \\
\text { Access to third party battery charging only } \\
\text { access to stand-alone electrical appliance (e.g. solar later, solar phone charger) } \\
\text { Own limited power access for multiple home applications(e.g. solar home systems or power limited off-grid) } \\
\text { Poor-quality and/or intermittent AC connection } \\
\text { Reliable AC connection available for all uses }\end{array}$ \\
\hline Mechanical Power & $\begin{array}{l}0 \\
1 \\
2 \\
3 \\
4 \\
5\end{array}$ & $\begin{array}{l}\text { No households access to tools or mechanical advantages } \\
\text { Hands tools available for households tasks } \\
\text { Mechanical advantage devices available to magnify human/animal effort for most household tasks } \\
\text { Powered mechanical devices available for some household tasks } \\
\text { Powered mechanical devises available for most household tasks } \\
\text { Mainly purchasing mechanically processed goods services }\end{array}$ \\
\hline
\end{tabular}

Source: [4] 
The Measure and Definition of Access to Energy Systems by Households and Social Effects of Lack of Modern Energy Access

Table 2. Minimum standards for household energy access

\begin{tabular}{|c|c|}
\hline Energy service & Minimum Standard \\
\hline Lighting & $300 \mathrm{~lm}$ for a minimum of 4 hours per night at household \\
\hline $\begin{array}{l}\text { Cooking and water } \\
\text { heating }\end{array}$ & $\begin{array}{l}1 \mathrm{~kg} \text { wood fuel or } 0.3 \mathrm{~kg} \text { charcoal or } 0.04 \mathrm{~kg} \mathrm{LPG} \text { or } 0.2 \text { liters of kerosene biofuel per person per day, taking less than } \\
30 \text { minutes per household per day to obtain } \\
\text { Minimum efficiency of improved solid fuel stoves to be } 40 \% \text { greater than a three-stone fire in terms of fuel use } \\
\text { Annual mean concentrations of particulate matter }\left(\mathrm{PM}_{2.5}<1010 \mu \mathrm{g} /\right. \\
\mathrm{m}^{3} \text { in households, with interim goals of } 15 \mu \mathrm{g} / \mathrm{m}^{3}, 25 \mu \mathrm{g} / \mathrm{m}^{3} \text { and } 35 \mu \mathrm{g} / \mathrm{m}^{3}\end{array}$ \\
\hline Space heating & Minimum daytime indoor air temperature of $18^{\circ} \mathrm{C}$ \\
\hline Cooling & $\begin{array}{l}\text { Households can extend life of perishable products by a minimum of } 50 \% \text { over that allowed by ambient storage } \\
\text { Maximum apparent indoor air temperature of } 30^{\circ} \mathrm{C}\end{array}$ \\
\hline $\begin{array}{l}\text { Information and } \\
\text { communications }\end{array}$ & $\begin{array}{l}\text { People can communicate electronic information from their } \\
\text { household } \\
\text { People can access electronic media relevant to their lives and } \\
\text { livelihoods in their household }\end{array}$ \\
\hline
\end{tabular}

Source: [4]

\section{Social Effects of Lack of Modern Energy Access}

In the PPEO 2014 report, energy access for households is divided into five major categories as a result of the data obtained from studies in Africa, Asia and Latin America. These; lighting, cooking and water heating, space heating, cooling and communication.

\subsection{Lighting}

Lighting is one of man's basic needs. As a result of lack of access to electricity, people are forced to resort to various means for lighting. Gas lamps and candles as well as providing low quality lighting which cause environmental pollution in both materials are used. This causes many health problems. Vulnerable candles and wick lamps lead to injury is the leading cause of death, particularly among women and children. Africa at Colombo National Hospital from 1998 -1999 year, the hospital admitted 487 patients (31\%) were found to be 151 burns from kerosene lamps [6]. Lighting in the light of the factors that determine the quality of access and lighting costs.

The quality of light: A $100 \mathrm{~W}$ light bulb is 1,300 lumens [4]. Kerosene lamp or a candle is only 11 lumens. So the amount of light emitted to the atmosphere is very small. The Minimum standard for adequate lighting levels to be able to meet in a house with incandescent light is acceptable $30 \mathrm{~W}$ lamp. It is sufficient for reading and other chores around 300 lumens. However, this should be available for at least four hours a night [7].

Another problem of lighting is the cost. Studies show that the cost of illuminating gas and candles is much higher than electricity. A World Bank study in Guatemala found that the household purchase price for a unit of light was 0.08 US\$ per
kWh for mains electricity compared to 5.87 for kerosene and 13.00 for candles, making them 162 times more expensive than mains electricity per unit of light [4].

\subsection{Cooking and Water Heating}

Cooking and water heating is not only a process that needs of the household, but also hospitals, schools, factories vb. is a process carried out in many places. According to the study, two of every five people in Africa (2.8 billion in 2010) wood for cooking, use charcoal or animal waste [8]. Advanced water heating, cooking and being able to access the technology has far-reaching effects. One of the more important that the workload of women and children, loss of time, health problems and the environmental pollution.

Women spend the time and workload to collect fuel: Especially in rural areas where modern energy services are not available and they spend too much time cooking food in inefficient stoves. The women's studies in various countries to collect firewood two children were found to spend time with 8 hours per day. The collection of these species varies in terms of fuel and seasonal availability [9]. Cooking worldwide who are spending an average of 6.5 hours per week to this work. Cook meals while leaving time up to 7 hours for women, men fall in 5 hours. High in the hills of Nepal has seen an average of 19 hours per week collected fuel. It is also inefficient stoves for cooking leads to a waste of time. For cooking in India and Ukraine consumed more time than 13 hours a week, week in Brazil in 5.2 hours, 4.9 hours in Turkey, leaving 3.7 hours to cook food in South Korea [10].

Health problems: Low-income people, many of the health problems and the factors that lead to death and primitive cooking stoves are used to heat water and bio-fuels. WHO (World health organization) in developing countries, 
according to forecasts as the fourth worst risk factors exposed to smoke during simple cooking, diseases and years leads to four million premature death [8]. Indirectly, according to estimated figures are 4.3 million deaths every year from indoor air pollution. The cause of death of more than half of children under age five, pneumonia at home during cooking exposed by inhaling the smoke particles and burns are caused by substances. Burns is an additional risk. According to WHO estimates 300,000 with only fire deaths occur. The average age is between 5-29 deaths caused by fire [11].

Environmental pollution: Emissions from burning solid fuels in open areas and traditional stoves have significant global warming effects, due to incomplete combustion, and where biomass is sourced from non-renewable supplies [4].

Minimum standards for cooking energy: The minimum standard for access to clean cooking solutions should cover fuel use, time, stove efficiency and pollution [4]. Standards developed by international organizations are:

- $1 \mathrm{~kg}$ wood fuel or $0.3 \mathrm{~kg}$ charcoal or $0.04 \mathrm{~kg}$ LPG or 0.2 litres of kerosene or biofuel per person per day, taking less than 30 minutes per household per day to obtain.

- Minimum efficiency of improved solid fuel stoves to be $40 \%$ greater than a three-stone fire in terms of fuel use

- Annual mean concentrations of particulate matter $\left(\mathrm{PM}_{2.5}\right)<10 \mu \mathrm{g} / \mathrm{m}$. in households, with interim goals of $15 \mu \mathrm{g} / \mathrm{m} ., 25 \mu \mathrm{g} / \mathrm{m}$. and $35 \mu \mathrm{g} / \mathrm{m}[4]$.

\subsection{Space Heating}

Space heating is an important function of household stoves and heating appliances, particularly at higher altitudes and during cold seasons. Despite this, it is often overlooked by policymakers and designers of stoves programmes. Depending on customs and traditions, people either want to use their cooking stove to also provide warmth, or they have a separate stove for heating their home. It is estimated that half a billion people in South and South-East Asia alone use stoves for space heating, whether for everyday use, just during cooler seasons or at night [12]. In the mountainous areas of Asia, households generally use $70-80 \%$ of primary energy directly for cooking and $20-25 \%$ directly for space heating. However, when the actual service provided by the energy is calculated, an estimated $60 \%$ contributes to heating the surrounding space and only $40 \%$ goes into cooking [12]. This is because much of the heat generated by the cook stove dissipates into the surrounding air, thereby heating the room. Improved stoves focus much more of this escaped heat on the pot, funnelling smoke and hot gases out through a flue or chimney. The unfortunate trade-off of this efficiency is that householders might need to have a separate fire to keep warm [13].

Health effects: It is difficult for low-income households to keep the domestic temperature high during the cold seasons. If there is not enough temperature, many health problems arise. In particular at temperatures below $20-25^{\circ} \mathrm{C}$ due to increased mortality of cardiovascular and respiratory diseases increases with time. HelpAge International (2009) reported that older people (and small children in their care) have been severely affected in Kyrgyzstan, where the capacity to generate hydroelectric power during the long winter months has been limited. To reduce their fuel consumption and costs, people often close the doors and windows. This exacerbates the amount of smoke in the house and exposes people to greater risks associated with indoor air pollution [4].

Minimum standards for space heating: Considering the health impacts of lower temperatures, we propose a minimum standard for daytime indoor air temperature of $18^{\circ} \mathrm{C}$. This should be achieved by means that do not entail indoor smoke, are affordable, and do not require excessive time in collecting fuel [4].

\subsection{Cooling}

Cooling is a critical energy services for the protection of food and medicine. The majority of developing countries located in the world's hottest regions, the annual average ambient temperature of almost four billion people more than $22^{\circ} \mathrm{C}$. South Asia, and more than a billion people living in South Africa, the annual average temperature of $30^{\circ} \mathrm{C}$.

Food preservation: Maintaining the average annual temperature for a long time and deterioration of food in places with high cooling is very important to stay fresh. That's why food production is seasonal in hot climates. Since there is good storage conditions, the animals are rarely cut. This brings with it many problems. In 2010 it was determined that approximately 830 million people are malnourished [14]. Improving post-harvest food preservation could help reduce this. A number of preservation methods are possible, including cooling, drying and curing. Cooling is often preferred since the produce is not significantly changed by the process. Data from five South American countries with high electrification rates show that refrigeration is a high priority for people of all income groups [4]. According to the results of poor people fridge with television from five countries in Africa (20\%) is for a primary device [6].

\subsection{Information and Communication}

Information which is defined as sending information by electronic means and communication technology (ICT) is an important tool to reduce poverty. The ICT sector is considered to contribute to economic growth. ICTs (such as radio, televisions, computers) are by their nature heavily dependent on energy and those without it lack access to information that could make a real difference in their lives: information about the composition and delivery of services from public institutions, about political activities and their human rights, about the market value of their goods and produce and about education and livelihoods options [4]. 
In By mid-2012, there were 2.4 billion internet users worldwide (34\% of the global population) (Internet World Stats), and 3.2 billion mobile phone subscribers. The growth in access has been rapid. However, there is still a risk that inequitable access to ICTs may exacerbate growing inequalities in income, knowledge and power between men and women, income or ethnic groups, or urban and rural populations. For example, a woman is $23 \%$ less likely than a man to own a mobile phone if she lives in sub-Saharan Africa and $37 \%$ less likely if she lives in South Asia[4].

\section{Conclusions}

This study shows that there is a direct correlation between the development of countries and energy access. Although energy is principally a private business in most countries, providing energy access for rural areas has traditionally been considered an essential public good for which governments are primarily responsible. Governments, rather than the private sector, must take responsibility for financing schools, clinics, and roads. Government subsidies are typically used to extend electricity grids and provide the poor with petroleum fuels. Providing similar support for renewable energy technologies can help spur their development [15].

Some of the steps needed to do to improve access to energy in developing countries include:

- Firstly, the areas that cannot be accessed should be identified, and then feasibility studies for these areas should be done.

- Standardize energy prices appropriately

- Strengthen the capacity of energy technologies and services at local level

- To allocate funds for the provision of energy services.

Thanks to today's technology, some solutions have been introduced for areas with lack of energy access. Thus, it is tried to solve the problems that households are caused by lack of energy. Renewable energy technologies (RET) are very suitable to modern energy services for low-income people. Combined with the rapid growth of solar, wind, geothermal and biomass energy, ongoing technology improvements and cost reductions, low-income people will be able to mitigate the lack of energy access. Promotion of any source of energy supply, including RETs, should be linked with wider rural development initiatives. RETs are one set of tools to provide a service. Governments are increasingly integrating RETs into electrification plans for rural off-grid energy-service delivery, with health and education applications being important entry points for government intervention. Governments can also encourage the appropriate use of RETs by supporting compelling and reliable assessments of renewable resources. These assessments increasingly drive supportive policy development and resulting investment. In many developing countries, some of the methods applied for regions with lack of energy access are as follows:
- Small wind power for water pumping and local electricity

- Solar photovoltaics for local electricity

- Solar collectors for water and space heating

- Ethanol and biodiesel for agriculture and transportation

- Geothermal energy for heat and grid electricity

The world of renewable energy in rural areas (small-grid systems) meets the power requirements at an exponential rate. In 2040, a total of approximately one billion people are expected to gain access to electricity through renewable energy sources, but is still more than half a billion people will still live a life deprived of electricity [15].

\section{REFERENCES}

[1] WEO (2016) Available from: http://www.worldenergyoutlook .org/media/weowebsite/energymodel/documentation/Energy Access_Methodology_2016.pdf[Accessed 05 Jan 2016].

[2] HEDON - E-Consult - Defining Energy Access.pdf [Accessed 10 Jan 2017]

[3] IEA (2014) World Energy Outlook 2011, Paris: International Energy Agency.

[4] Practical Action (2014) Poor people's energy outlook 2014, key messages on energy for poverty alleviation: Practical Action Publishing.

[5] Bazilian, M., Nussbaumer, P., Cabraal, A., Centurelli, R., Detchon, R., Gielen, D., Rogner, H. Howells, M., McMahon, H., Modi, V., Nakicenovic, N., O'Gallachoir, B., Radka, M., Rijal, K., Takada, M., Ziegler, F. (2010) Measuring energy access: Supporting a global target, Earth Institute, Columbia University, New York.

[6] Kozulj, R. (2009) Contribution of energy services to the Millennium Development Goals and to poverty alleviation in Latin America and the Caribbean. Economic Commission for Latin America and the Caribbean (ECLAC) United Nations, Santiago, Chile. Available from: http://www.eclac.org/publicaciones/xml/0/38790/lcw281i.pd f [Accessed 08 Apr 2014].

[7] CGDEV (2009) Africa's private sector: What's wrong with the business environment and what to do about it, by V. Ramachandran, A. Gelb, and M. Kedia Shah, Centre for Global Development, Washington DC. Available from: http://www.cgdev.org/content/publications/detail/1421340/ [Accessed 05 Apr 2015].

[8] Banerjee, S. G., Bhatia, M., et al. (2013) Global tracking framework. Vol. 3 of Global tracking framework. Sustainable Energy for All. Washington DC: The World Bank.http://documents.worldbank.org/curated/en/2013/05/17 765643/global-tracking-framework-vol-3-3-main-report [Accessed 08 Apr 2014].

[9] Dutta, S. and Clancy, J.S. (2005). Women and productive uses of energy: Some light on a shadowy area. Paper presented at the UNDP Meeting on Productive Uses of Renewable Energy, Bangkok, Thailand. 
[10] Barnes, D. (2010) Measuring household lighting: survey design issues. Energy for Development and Poverty Reduction [blog], 6 March. Available from: http://www.energyfordevelopment.com/2010/03/measuringhousehold-lighting.html [Accessed 08 Apr 2014].

[11] WHO (2012) World Health Statistics, Available from: http://www.who.int/gho/publications/world_health_statistics /en/ [Accessed 10 Apr 2015].

[12] Hulscher, W. (1997) Stoves for space heating and cooking at different altitudes and/by ethnic groups. Regional Wood
Energy Development Programme in Asia (RWEDP) Report, No. 28.

[13] Practical Action (2012) Poor people's energy outlook 2012, Rugby, UK: Practical Action Publishing.

[14] EC (2006) The role of energy services in the health, education and water sectors and cross-sectoral linkages, Brussels: European Commission

[15] Renewable Energy for the 21st Century (REN21) Web site, at www.ren21.net. [Accessed 15 Jan 2017]. 